\title{
FATORES DA MODERNIZAÇÃO AGRÍCOLA NO PARANÁ PARA OS ANOS DE 1995 E 2006
}

\section{AGRICULTURE MODERNIZATION FACTORS AT PARANA FOR THE YEARS 1995 AND 2006}

\author{
Edson Ramos de Medeiros \\ Universidade Norte do Paraná -- Londrina - PR - Brasil \\ Marcia Regina Gabardo da Camara \\ Universidade Estadual de Londrina - Londrina - PR - Brasil \\ Carlos Eduardo Caldarelli \\ Universidade Estadual de Londrina - Londrina - PR - Brasil \\ Vanderlei José Sereia \\ Universidade Estadual de Londrina - Londrina - PR - Brasil
}

\begin{abstract}
Resumo: O objetivo deste estudo é analisar os determinantes da modernização do setor agrícola do Paraná para os anos de 1995 e 2006. A fonte de dados utilizada foi o Censo Agropecuário do Instituto Brasileiro de geografia e Estatística-IBGE. Dois métodos foram empregados para o tratamento e análise de dados, a saber: análise fatorial e análise espacial de dados. A análise fatorial permitiu construir o Índice de Modernização Agrícola-IMA e a Análise Exploratória de Dados Espaciais-AEDE possibilitou verificar padrões de concentração espacial do índice. Os resultados mostram que os indicadores que mais contribuíram na formação do IMA foram, respectivamente: a maquinaria; adubos e corretivos; sementes e mudas; defensivos agrícolas e; irrigação. Foram identificados três clusters de baixo IMA e seis clusters de alto IMA no Estado. Este estudo permitiu concluir que os clusters de baixo IMA ocorrem em áreas de baixo Índice de Desenvolvimento Humano-IDH, de relevo e solo inaptos ou com restrições à mecanização, de menor fertilidade, vulneráveis à erosão, baixa produtividade agropecuária e pouco capitalizada. Por outro lado, os clusters de alto IMA ocorrem em áreas de melhores IDH, com relevo apto à mecanização, solos férteis e com baixa restrição à produção agropecuária, em suma, regiões de alta produtividade e capitalização.
\end{abstract}

Palavras-chave: Modernização Agrícola. Análise Fatorial. Análise Espacial. Paraná.

Abstract: The aim of this paper is to analyze factors of the modernization of the agricultural sector of Paraná for the years 1995 and 2006. The Census (IBGE) data were 
used. Two methods for the treatment and analysis of data were used: Factor analysis and spatial data and analysis. The factor analysis allowed the construction of the Index of Agricultural Modernization (IAM); the next step was to adopt Exploratory Spatial Data Analysis (ESDA) to determine patterns of spatial concentration. The results showed that the indicators that contributed in the formation of IMAs were machinery, fertilizers and correctives, seeds and seedlings, pesticides and irrigation, respectively. Three clusters of low IAM and six clusters of high IAM were identified. Regarding the characteristics of clusters of Iow IMA, we verify that they occur in areas of low HDI, topography and soil unfit or restricted to mechanization, lower fertility, vulnerable to erosion, low agricultural productivity and poorly capitalized. The clusters of high IAM occur in areas of best HDI (Human Development Index) with flat relief mechanization, fertile and low constraint to agricultural production soils strongly related to high productivity and capitalization.

Keywords: Agricultural Modernization. Factor Analysis. Spatial Analysis. Paraná 


\section{INTRODUÇÃO}

Segundo Souza e Lima (2003), a partir da II Guerra Mundial, o meio rural brasileiro sofreu alterações relevantes, principalmente tecnológicas. Tais mudanças intensificam-se, sobretudo, a partir da década de 1960, quando o setor agrícola inicia mais fortemente o processo de modernização. Esse processo caracterizou-se pela utilização de um conjunto de instrumentos, ações, projetos e programas, sobretudo coordenados pelo Estado. Dessa nova realidade, verificou-se uma interação do setor agrícola com a dinâmica industrial, provocando uma mudança da base técnica do setor. Esse processo caracterizou a primeira fase da modernização agrícola brasileira. Com forte apoio do Estado, esse movimento consolidou-se com a formação dos complexos agroindustriais, passando a agricultura brasileira de complexo rural a agroindustrial nos anos 1970 (KAGEYAMA; GRAZIANO DA SILVA, 1987).

O período subsequente, que compreende o fim da década de 1970 e o início dos anos 1980, é marcado pela falência desse modelo fortemente subsidiado pelo Estado (MARTINE, 1991). Tal fato ocorre, segundo Buainain, Vieira e Lima (2010), em virtude da crise macroeconômica e das mudanças estruturais vividas no período. Como reflexo, tem-se uma forte retração dos subsídios, o que inicia a transição para um modelo menos intervencionista e com menor ação do Estado.

Ao final dos anos 1980 e início da década de 1990, verifica-se o fim desse período de transição, com a desmontagem de todo o aparato do Estado no que concerne à intervenção no setor rural (MARTINE, 1991). Assim, a partir dos anos de 1990, tem-se um novo modelo de ordem liberal e globalizado para o setor agropecuário brasileiro, orientado, principalmente, pelo mercado.

No bojo dessa discussão, o objetivo deste estudo é analisar os determinantes da modernização do setor agrícola do Paraná para os anos de 1995 e 2006. Para tanto, procede-se à mensuração e análise do IMA dos municípios paranaenses. Entre as razões que justificam a escolha do Estado do Paraná como objeto desta pesquisa, destaca-se a importância e participação de sua produção no setor agropecuário brasileiro e a importância deste setor para a geração de emprego e renda no Estado. A análise da dinâmica tecnológica e sua dimensão 
espacial no Paraná é a principal contribuição do presente trabalho, pois analisa a evolução do setor agrícola no Estado pós-1990.

\section{ESTUDOS TEÓRICOS E EMPÍRICOS SOBRE A MODERNIZAÇÃO AGRÍCOLA}

Segundo Graziano da Silva (1990), o setor agrícola apresenta especificidades no tocante ao progresso tecnológico. Tal setor possui fatores naturais, além dos fatores fabricados, também presentes no setor industrial - máquinas, equipamentos e meios de produção em geral -, compreendidos por tipos e fertilidades do solo, topografia, clima, etc. Dessa forma, devido à existência de fatores naturais, não é possível que a produção do setor agrícola seja plenamente controlada.

Mielitz Netto, Melo e Maia (2010) apontam que a existência de elementos naturais faz com que o homem seja forçado a respeitar alguns aspectos da natureza, tais como: período de maturação dos vegetais, fatores biológicos ou, de forma mais abrangente, os chamados fatores não controláveis.

Dadas tais especificidades existentes no setor agrícola, Graziano da Silva (1996) considera relevante o avanço tecnológico das forças produtivas em geral, sobretudo na indústria química, mecânica, avanços na genética e tecnologia agronômica, porquanto estes avanços permitem reduzir o tempo do ciclo produtivo, ou melhor, reduzir a influência dos fatores naturais. Entende-se que a modernização agrícola é um fator preponderante para melhor desempenho do setor, pois trata de subordinar o processo de produção à lógica do capital. Em outras palavras, significa subordinar a natureza ao capital.

Segundo Salles Filho (1993, p.31-32), a tecnologia agropecuária é de caráter multidisciplinar, pois envolve "o manejo de condições físicas, tais como propriedades do solo e oscilações climáticas de umidade, temperatura e insolação; químicas, como as condições de disponibilidade de elementos essenciais em determinadas formas moleculares; e biológicas", além de propriedades de natureza mais complexa, que envolvem o "funcionamento dos organismos individualmente (plantas, animais e microrganismos) e os efeitos de suas inter-relações e das interações com o meio". O autor também destaca as complementariedades concernentes ao processamento de produtos agrícolas que vão exigir que tais tecnologias potencializem a mecanização e a industrialização dos produtos cultivados no campo, 
sinalizando avanços no conhecimento da complexa interação existente nas relações "clima-solo-planta-animal" no novo padrão tecnológico resultante da modernização do campo.

A segunda característica importante é a integração agrícola aos segmentos industriais, definindo um padrão baseado no uso de técnicas e insumos complementares, cujas origens são internas e externas à propriedade que envolve a "concorrência de várias indústrias, de instituições públicas de pesquisa e de segmentos ligados à prestação de serviços, com seus diferentes mercados, áreas de conhecimento e padrões inovativos distintos, além de métodos particulares de produção e de organização da produção". Portanto, de natureza complexa, segundo Salles Filho $(1993,34)$.

A terceira característica da tecnologia agropecuária é que sua finalidade é o aumento da produtividade da terra e do trabalho. De forma que, segundo Salles Filho (1993, p. 34), o "uso de máquinas, sementes melhoradas, fertilizantes e pesticidas, neste padrão, busca acréscimos de produtividade, das quantidades produzidas por unidade de área ou de trabalho."

Delgado (1985) e Graziano da Silva (1996) classificam as inovações agrícolas em: mecânicas, físico-químicas, biológicas e agronômicas. Com relação às inovações mecânicas, que compreendem as máquinas e implementos agrícolas, essas funcionam como no setor industrial, ou seja, promovem aumento da produtividade mediante aumento da intensidade e do ritmo de trabalho, e também por meio da redução do tempo de trabalho necessário para execução uma dada atividade, contudo, ressalta-se que o período de produção pouco sofre alteração. Assim, o processo de mecanização afeta o modo produção e a intensidade da jornada de trabalho, mantendo o tempo do ciclo produtivo praticamente inalterado, reduzindo de forma significativa $o$ tempo de não trabalho o que eleva a velocidade de rotação do capital.

As inovações físico-químicas correspondem à utilização de defensivos químicos, adubos, corretivos de solo e fertilizantes. Os defensivos promovem aumento da produtividade e redução do tempo de trabalho, em virtude, como menciona Graziano da Silva (1996), da redução das perdas provenientes de aspectos naturais. No que se refere à utilização de adubos e corretivos de solo, esses contribuem para a elevação da produtividade da terra e do trabalho, mas não necessariamente uma menor utilização do fator trabalho, visto que com 
solos mais produtivos tem-se, com a mesma quantidade de trabalho, uma maior produção, ou seja, o aumento da produtividade do trabalho ocorre em consequência do aumento da produção - elevação da produtividade da terra.

As inovações agronômicas correspondem à utilização de novos procedimentos, métodos e práticas culturais e compreendem as formas de organização da produção e do fator trabalho, formas de plantio, rotação de culturas, sistema de manejo de solos e animais etc. Estas, além de promoverem o aumento significativo da produtividade, reduzem custo e, consequentemente, permitem maior lucratividade, funcionando como importante elo para implementação dos demais tipos de inovação no meio agrícola.

As inovações biológicas correspondem ao uso de sementes e mudas geneticamente modificadas. Tais inovações permitem acelerar, ou até mesmo transformar, aspectos naturais do processo produtivo, do ciclo produtivo, submetendo, assim, a natureza ao uso do capital. Isso, por sua vez, vem a potencializar e acelerar os efeitos dos demais tipos de inovações e, consequentemente, os efeitos do progresso tecnológico no setor agrícola. Segundo Salles Filho (1993), o desenvolvimento das agrobiotecnologias pode prover soluções biológicas que permitem o controle de pragas e doenças com menores danos ao meio ambiente, fertilização mais sustentável e menos poluidora dos solos, contribuindo, adicionalmente, para a melhoria genética das espécies, entre outras vantagens.

Segundo Graziano da Silva (1990) e Delgado (1996), todas as formas de melhoria tecnológica exercem seu papel no aumento da produtividade - do trabalho e da terra -, sendo as inovações agronômicas e biológicas a base para o aumento da lucratividade no meio agrícola, visto que permitem, de forma mais significativa, reduzir o tempo de produção, o ciclo produtivo, em suma, o tempo de trabalho necessário para produção de determinado bem.

Nesse contexto, apresentam-se estudos empíricos selecionados que debatem o tema para o Brasil. O estudo de Souza e Lima (2002) destaca a intensidade e a dinâmica da modernização agrícola no país e utiliza análise fatorial para a criação de um índice de modernização do setor. Os aludidos autores utilizam variáveis relacionadas ao emprego das principais tecnologias modernas no Brasil. Os autores verificam que, entre 1975 e 1995, os estados apresentam intensidades de 
modernização agrícola e características diferenciadas e, após a década de 1980 há evidências de uma retração da modernização, que seria fruto, sobretudo, da redução da oferta de crédito.

Ferreira Júnior, Baptista e Lima (2004) realizam estudo para o Estado de Minas Gerais, distinguindo suas microrregiões quanto ao seu grau de modernização do campo. Os autores utilizam a análise multivariada e verificam, em seus resultados, dez grupos diferentes de microrregiões homogêneas, com combinações distintas dos fatores encontrados, o que reflete o seus níveis tecnológicos. Silva e Fernandes (2005), por sua vez, desenvolvem estudo voltado para o setor agropecuária da região Norte do país e verificam elevada heterogeneidade no tocante à modernização agrícola, que apresenta, de forma geral, baixos níveis de modernização. Os estados do Amazonas e Amapá apresentam os melhores resultados, enquanto Roraima e Tocantins, os piores.

Para a realidade paranaense, foram analisados os estudos de Llanillo et al. (2006) e de Melo e Parré (2007). O estudo de Llanillo et al. (2006) utilizou a análise fatorial para caracterizar a estrutura agropecuária do Paraná para 1995/1996 e classifica dez tipos de municípios distribuídos em nove mesorregiões, mostrando a diversidade agrícola do estado. O estudo concluiu que os indicadores da modernização agrícola se mostraram fortemente relacionados às variáveis que captam intensidade do uso da terra. Verificou-se, também, nesse estudo a heterogeneidade entre as regiões do estado; foram identificadas áreas com significativos índices de modernização e outras com níveis de modernização baixos.

Melo e Parré (2007) também utilizam análise fatorial para construir um índice de desenvolvimento rural para o Paraná, procurando hierarquizar e identificar os fatores determinantes que promovem o desenvolvimento dessas áreas rurais. Os resultados mostraram que a maior parte dos municípios ficou abaixo do índice médio e que existiam municípios com diferentes níveis de tecnologia e uma assimetria na modernização agrícola no estado.

No tocante aos estudos espaciais voltados para o meio rural brasileiro, destaca-se o estudo pioneiro de Perobelli et al. (2007), que analisou a influência de efeitos espaciais sobre a produtividade agrícola do Brasil para os anos de 1991, 1997 e 2003. O estudo verificou que a produtividade agrícola se mostra autocorrelacionada com o espaço, 
identificando quatro clusters de alto desenvolvimento, sendo dois no Estado de São Paulo e Centro Oeste o e outro no litoral nordestino. Pinheiro e Parré (2007) analisam a distribuição espacial da produtividade da cana-de-açúcar no Estado do Paraná. Os resultados apontam autocorrelação espacial positiva entre as microrregiões, sendo o Norte do Paraná a principal região produtora de cana em virtude dos fatores edafoclimáticos.

O estudo de Almeida, Perobelli e Ferreira (2008), por sua vez, discute a convergência espacial da produtividade agrícola da terra para as microrregiões brasileiras. $O$ estudo mostra evidências da convergência absoluta da produtividade agrícola brasileira nas microrregiões, indicando que a produtividade agrícola no Brasil está convergindo para a média, contudo a uma taxa muito lenta.

Entre os trabalhos mais recentes referentes ao Paraná, destacamse o de Pinheiro (2007) e Pavan (2013). Pinheiro (2007) estima a função de produção agropecuária paranaense para o ano de 2002 e utiliza técnicas de econometria espacial, verificando que existe correlação espacial entre os municípios, sendo os localizados no Norte e Oeste paranaense os com maiores valores, onde são identificados dois clusters de alto desenvolvimento. Quanto à função de produção, verifica-se que esta não segue a mesma estrutura nos municípios, sendo que a localização destes, bem como sua vizinhança, interfere na produção agrícola dos mesmos. Por fim, registra-se ainda uma supremacia do Oeste e Norte do Paraná na produção agropecuária.

Pavan (2013) estima um modelo espacial econométrico para explicar a distribuição da produtividade agrícola entre os municípios do Paraná em 2010. Como resultado, verificou-se a autocorrelação espacial positiva, a heterogeneidade espacial das variáveis e a identificação da formação de clusters de alta produtividade nas regiões Metropolitana, Centro-Oriental, Oeste e Sudoeste.

\section{Modelo Teórico}

\subsection{Base de dados e variáveis utilizadas}

O presente estudo, por meio de indicadores de transformação tecnológica, analisa as mudanças na agricultura nos municípios paranaenses pós-1990. A amostra utilizada tem como base os Censos 
Agropecuários do IBGE para os anos de 1995 e 2006. As variáveis selecionadas são de cunho tecnológico e foram utilizadas em estudos como os de Hoffmann (1992), Souza e Lima (2003), Kageyama (2004), Vidal et al. (2007), Melo e Parré (2007) e Souza et al. (2009), corroboradas, portanto, na literatura como indicadores adequados para a proposta deste estudo. A amostra possui 18 variáveis puras ${ }^{1}$ e utiliza 35 indicadores $^{2}$. As 18 variáveis puras são apresentadas no Quadro 1 (APÊNDICE I).

As informações coletadas junto aos Censos Agropecuários (1995 e 2006) traduzem a evolução das características tecnológicas desse setor. As variáveis de cunho tecnológico coletadas são: mecânica (tratores, máquinas para plantio, máquinas para colheita); montante de investimento e despesas realizadas; e físico-química (adubos e corretivos, calagem ${ }^{3}$ e utilização de irrigação, sementes etc.). Além da análise do processo de modernização, o presente estudo procura verificar a sua intensidade. Os estudos de Hoffmann (1992), Souza et al. (2009), Souza e Lima (2003), Vidal et al. (2007), Kageyama (2004), Melo e Parré (2007) foram utilizados como base para a construção do IMA.

\subsection{Análise fatorial}

O presente estudo utiliza análise fatorial para mensurar o processo de modernização (progresso técnico) do setor agropecuário no Estado do Paraná. O procedimento e as variáveis utilizadas para mensurar o grau de modernização da agropecuária foram selecionados a partir de trabalhos de Hoffmann (1992), Ponciano et al. (2009), Souza e Lima (2003), Vidal, Silva e Mendonça (2007), Silva e Fernandes (2005) e Ferreira Júnior, Baptista e Lima (2004).

Segundo Corrar et al. (2012), Souza e Lima (2003) e Schilderinck (1970 apud Souza et al., 2009), o método de análise fatorial consiste em determinar as relações quantitativas entre as variáveis, associando àquelas com um padrão semelhante o efeito de um fator causal subjacente e específico a estas variáveis, ou seja, a análise fatorial avalia

\footnotetext{
1 Pura no sentido de bruta, coletadas nos censos agropecuários, não intensificadas, ou melhor, sem ser relativizada por outra variável.

2 Variáveis intensificadas expressam uma razão entre duas dadas variáveis puras.

3 Uso de calcário para correção do PH do solo.
} 
a probabilidade de agrupar $i$ variáveis $\left(X_{1}, X_{2}, X_{3}, \ldots X_{i}\right)$ em um número menor de $j$ fatores $\left(F_{1}, F_{2}, F_{3}, \ldots F_{j}\right)$.

De forma algébrica, pode ser expresso por:

$$
X_{i}=\alpha_{i 1} F_{1}+\alpha_{i 2} F_{2}+\alpha_{i 3} F_{3}+\cdots+\alpha_{i j} F_{j}+\varepsilon_{i}
$$

Sendo:

$X_{i}$ variáveis padronizadas 4 ;

$\alpha_{i}$ as cargas fatoriais responsáveis pela combinação linear entre

os fatores comuns; $F_{1}, F_{2}, F_{3} \ldots F_{j}$ os fatores comuns não

relacionados entre si; e

$\varepsilon_{i}$ o termo de erro, que expressa a parcela de variação da variável $i$ não explicada.

Quanto às cargas fatoriais $\left(\alpha_{i}\right)$, estas expressam o grau de relação entre as variáveis originais (padronizadas) e os fatores. Desta forma, quanto mais elevado o valor destas cargas mais forte se apresenta a relação entre tais variáveis (CORRAR et al., 2012, MELO; PARRÉ, 2007).

No que concerne aos fatores, estes podem ser encontrados e estimados por uma combinação linear das variáveis originais (padronizadas), genericamente expressa por:

$$
\begin{gathered}
F_{j}=\omega_{j 1} X_{1}+\omega_{j 2} X_{2}+\omega_{j 3} X_{3}+\cdots+\omega_{j i} X_{i} \\
F_{j}=\sum_{i=1}^{i} \omega_{j i} X_{i}
\end{gathered}
$$

Em que:

$F_{j}$ são os fatores comuns não relacionados;

$\omega_{j 1}$ os coeficientes de escores fatoriais;

$X_{i}$ as variáveis originais (padronizadas); e

$i$ o número de variáveis.

Assim, encontrados os fatores e os escores fatoriais, busca-se, em seguida, mensurar o grau de modernização agrícola do Paraná e, para tanto, é utilizado um índice de desenvolvimento bruto (MELO; PARRÉ, 2007; SOUZA et al., 2009)

No que se refere à absorção de tecnologia, nomeada no presente estudo por IMA, esta é determinada por:

$$
I M A=\frac{\sum_{i=1}^{n} \omega_{i} F_{i}}{\sum_{i=1}^{n} \omega_{i}}
$$

\footnotetext{
${ }^{4}$ Consiste em expressar, em termos de desvios padrão, os desvios em torno da média das observações originais.
} 
Sendo:

IMA o índice de modernização agrícola, que corresponde à média ponderada dos escores fatoriais;

$\omega_{i}$ é a proporção da variância explicada por cada fator; e $F_{i}$ os escores fatoriais.

Após mensurar o IMA, utiliza-se a AEDE com intuito de verificar como se distribui espacialmente tal índice e identificar a formação de clusters do processo de modernização e seus respectivos impactos.

\subsection{Análise Exploratória de Dados Espaciais (AEDE)}

A AEDE, segundo Almeida (2012), consiste em um conjunto de técnicas para a análise estatística de informação geográfica, que tem por intuito descrever distribuições espaciais, identificar observações discrepantes no espaço (outliers), analisar padrões de associação espacial e identificar possíveis clusters espaciais. Essa análise permite calcular medidas de autocorrelação espacial global e local, possibilitando a investigação da influência dos efeitos espaciais. Para isso, são realizados testes formais para verificar a presença de autocorrelação espacial, a saber, as Estatísticas / de Moran Global e Local.

Segundo Almeida (2012) e Tyszler (2006), existem várias maneiras de construir a matriz de ponderação espacial. No presente estudo, utiliza-se a matriz tipo Queen, que considera como vizinhas as regiões que apresentem uma borda (ou fronteira) comum, bem como um nó comum (HADDAD; PIMENTEL, 2004). Um outro fato que se deve levar em consideração, de acordo com Almeida (2012), é que a técnica AEDE mostra-se mais adequada para variáveis densas ou intensivas, ou seja, variáveis divididas por algum indicador. Dessa forma, as variáveis mais comuns e adequadas para tal análise são variáveis per capita ou intensificadas. No presente estudo, a variável analisada é o IMA, que já é uma variável densa por se tratar de um indicador.

Associação Espacial Univariada: Global e Local

Para verificar a presença de autocorrelação espacial global e local, faz-se uso dos indicadores / de Moran Global, que captam o efeito 
global, e para o âmbito local, tem-se o / de Moran Local. Essas análises são realizadas por meio do Diagrama de Dispersão de Moran (Scatterplot) e das estatísticas LISA.

- Estatística / de Moran Global

Segundo Anselin (1999), o teste de verificação de autocorrelação espacial mais comumente utilizado é a estatística / de Moran, representada em notação matricial por:

$$
I=\left(\frac{N}{S_{0}}\right)\left(\frac{e^{\prime} W e}{e^{\prime} e}\right)
$$

Sendo:

$e$ o vetor de n observações em termos de desvios em relação à média;

$W$ a matriz de ponderação de pesos espaciais; e

$S_{0}$ é um escalar que iguala a soma dos elementos da matriz ponderação $(W)$.

Outra forma de expressar estatística / de Moran é sugerida por Almeida (2012):

$$
I=\frac{n}{\sum \sum W_{i j}} \frac{\sum \sum W_{i j}\left(y_{i}-\bar{y}\right)\left(y_{j}-\bar{y}\right)}{\sum\left(y_{i}-\bar{y}\right)^{2}}
$$

Sendo:

$n$ o número de unidades espaciais;

$y_{i}$ a variável de interesse;

$\bar{y}$ valor médio da variável de interesse; e

$W_{i j}$ o peso espacial para as unidades espaciais $i$ e $j$, onde este mede o grau de interação entre elas.

A estatística / de Moran fornece o grau de associação linear entre os vetores de valores observados em um tempo e a média ponderada dos valores dos seus vizinhos (BIVAND; PEBESMA; RUBIO, 2008). Tyszler (2006) afirma que a estatística / de Moran representa o valor do coeficiente de inclinação de uma reta de regressão de $W y$ contra $y$.

Após calcular a estatística / de Moran, é necessário calcular um valor esperado para a regra de decisão. Segundo Almeida (2012), esse é dado por $E(I)=-\left[\frac{1}{n-1}\right]$; o valor / de Moran calculado deveria ser igual a este valor esperado, significando que este seria o valor obtido caso não existisse padrão espacial nos dados. Se o valor / de Moran for maior que o seu valor esperado, verifica-se a presença de autocorrelação positiva, em caso inverso, verifica-se correlação negativa. 
- Estatística I de Moran Local

a) Diagrama de Dispersão de Moran (Moran Scatterplot)

A estatística / de Moran é um coeficiente de inclinação de uma dada regressão e, desta forma, o diagrama de dispersão de Moran é outra maneira de verificar a autocorrelação espacial, ou seja, de interpretar o / de Moran. Esse diagrama constitui-se de quatro categorias, representados pelos quadrantes $A A, A B, B A$ e $B B$ (de um eixo cartesiano), onde cada quadrante deste corresponde a um grau de associação entre uma dada área e seus vizinhos, conforme matriz de ponderação, ou seja, a formação de agrupamentos ou clusters (ALMEIDA, 2012; TEIXEIRA et al., 2008). Em que:

- $01^{\circ}$ quadrante $A A$ (A/to-A/to) representa áreas com valores acima da média, bem como as suas áreas vizinhas; ambos apresentam valores altos para a variável em estudo;

- O $2^{\circ}$ quadrante $B A$ (Baixo-Alto) representa áreas com baixos valores para a variável, contudo, seus vizinhos apresentam altos valores para esta mesma variável em estudo;

- O $3^{\circ}$ quadrante $B B$ (Baixo-Baixo) é constituído por áreas com baixos valores para a variável, bem como seus vizinhos que também apresentam baixos valores para a variável de interesse; e

- O $4^{\circ}$ quadrante $A B$ (A/to-Baixo) é formado por áreas que apresentam altos valores, ou seja, acima da média, porém, as suas áreas vizinhas registram baixos valores para a mesma variável de interesse.

As áreas que se encontram nos quadrantes $A A$ e $B B$ apresentam autocorrelação positiva. Nos quadrantes $B A$ e $A B$, verifica-se autocorrelação negativa (ALMEIDA, 2012).

b) Indicadores Locais de Associação Espacial (LISA)

Anselin (1995) sugere, como definição operacional, que um LISA deve atender dois requisitos para ser classificado como tal: i) deve possuir para cada observação uma indicação de clusters espaciais significantes de valores similares em torno da observação; e ii) a soma dos LISAs para todas as regiões é proporcional ao indicador de autocorrelação espacial global.

De maneira formal, o / de Moran Local é dado, segundo Anselin (1995) e Almeida (2012), por:

$$
I_{i}=z_{i} \sum_{j} w_{i j} z_{j}
$$


Sendo: $z_{i}$ e $z_{j}$ são variáveis padronizadas e a somatória $(\Sigma)$ sobre $j$ é tal que somente os valores dos vizinhos $j \in J i$ são incluídos. O conjunto $J i$ abrange os vizinhos da observação $i$.

O I de Moran Local também pode ser obtido pela seguinte equação:

$$
I_{i}=\frac{\left(y_{i}-\bar{y}\right) \sum_{j} w_{i j}\left(y_{j}-\bar{y}\right)}{\sum_{i}\left(y_{i}-\bar{y}\right)^{2} / n}
$$

Assim, sendo o / de Moran Local obtido (equação 7 ou 8), tem-se, sob a hipótese de aleatoriedade, que o valor esperado da estatística do $I_{i}$ é dado por: $E\left[I_{i}\right]=-w_{i} /(n-1)$, sendo o $w_{i}$ a soma dos elementos da linha (ANSELIN, 1995).

Segundo Perobelli et al. (2007), se o $I_{i}$ apresenta valores positivos, existem clusters espaciais com valores similares, ou seja, uma dada área e seus vizinhos apresentam semelhanças, sejam estes alto ou baixo. Contudo, quando este apresenta valores negativos, tem-se que existem clusters espaciais com valores diferentes entre uma dada área e suas áreas vizinhas.

\section{4 ÍNDICE DE MODERNIZAÇÃO AGRÍCOLA NO PARANÁ}

A análise descritiva das variáveis permite verificar, para os anos de 1995 e 20065, que entre as 18 variáveis coletadas, 11 apresentaram crescimento positivo, enquanto 7 apresentaram taxas negativas, conforme a Tabela 1. É possível verificar que a área explorada não apresenta alterações significativas, bem como o número de estabelecimentos que se mantém estável, enquanto o nível de pessoal ocupado apresenta redução de pouco mais de 13\%. Por outro lado, há uma significativa elevação da produção agrícola no período, com taxa de crescimento em seu valor superior a 50\%, caracterizando, assim, aumento da produtividade dos fatores terra e trabalho. Sugere-se que tais diferenças estejam relacionadas a uma maior utilização das

\footnotetext{
5 Ressalta-se, contudo, que devido a alterações neste período na divisão política municipal do Paraná (emancipação de 28 municípios), utilizou-se como artifício a composição dos municípios de 2006 idêntica nos dois períodos, isto é, a mesma divisão política municipal existente em 2006.
} 
inovações, sejam elas mecânicas, físico-químicas, biológicas ou agronômicas.

Ao observar os dados (Tabela 1) para a variável máquinas de força mecânica - proxy para inovações mecânicas -, verifica-se uma redução de aproximadamente 40 mil máquinas, representando 13,35\%. Entre as máquinas que compõem essa variável algumas registram quedas expressivas, com destaque para o número de máquinas para plantio, que apresentou redução de mais de 25\%, aproximadamente 21 mil máquinas a menos na frota do Estado. Embora as máquinas tenham diminuído em número, tornaram-se mais eficientes e com maior capacidade de plantio e colheita, tendo aumentado o consumo de equipamentos de maior potência, a exemplo do caso do uso de tratores.

Ainda de acordo com as informações da Tabela 1, a variável número de máquinas para colheita apresentou uma redução, sendo que a frota teve uma queda de pouco mais de 3,5 mil máquinas, representando uma taxa de quase $15 \%$, atingido ao fim de 2006 pouco mais de 20 mil máquinas. Por fim, no quesito de maquinaria, a variável número de tratores apresenta a maior frota em ambos os anos analisados, registra a menor redução em termos relativos, a menor taxa com pouco mais de $6 \%$ o que equivale a cerca de 8 mil tratores, e atinge ao fim do período uma frota com nível de aproximadamente $13 \mathrm{mil}$ tratores. A redução nas 4 variáveis no âmbito da maquinaria, concomitantemente com aumento de produção e produtividade, leva a crer que pode ter ocorrido uma intensificação do processo de modernização no Estado, com adoção de máquinas mais eficientes, potentes e produtivas.

Tabela 1. Comparativo das variáveis puras para o Paraná - 1995 e 2006

\begin{tabular}{|c|c|c|c|c|c|}
\hline$N$ & Variável & Unidade & 1995 & 2006 & $\begin{array}{c}\text { Variação } \\
\text { (\%) }\end{array}$ \\
\hline \multicolumn{6}{|c|}{ hectare/milhõe } \\
\hline 1 & área explorada & $\mathrm{s}$ & 14,57 & 14,51 & $-0,42$ \\
\hline 2 & pessoal ocupado & Milhões & 1,28 & 1,11 & $-13,24$ \\
\hline \multirow[t]{2}{*}{3} & total de estabelecimentos & Mil & 369.875 & 371.063 & 0,32 \\
\hline & & & $10.993,9$ & $16.735,1$ & \\
\hline 4 & produção* & $\mathrm{R} \$$ milhões & 0 & 3 & 52,22 \\
\hline 5 & máquinas de força mecânica & Mil & 301,2 & $260, .9$ & $-13,35$ \\
\hline \multirow[t]{2}{*}{6} & Tratores & Mil & 121,8 & 113,7 & $-6,66$ \\
\hline & número de máquinas para & & & & \\
\hline 7 & colheita & Mil & 23,9 & 20,3 & $-14,92$ \\
\hline
\end{tabular}




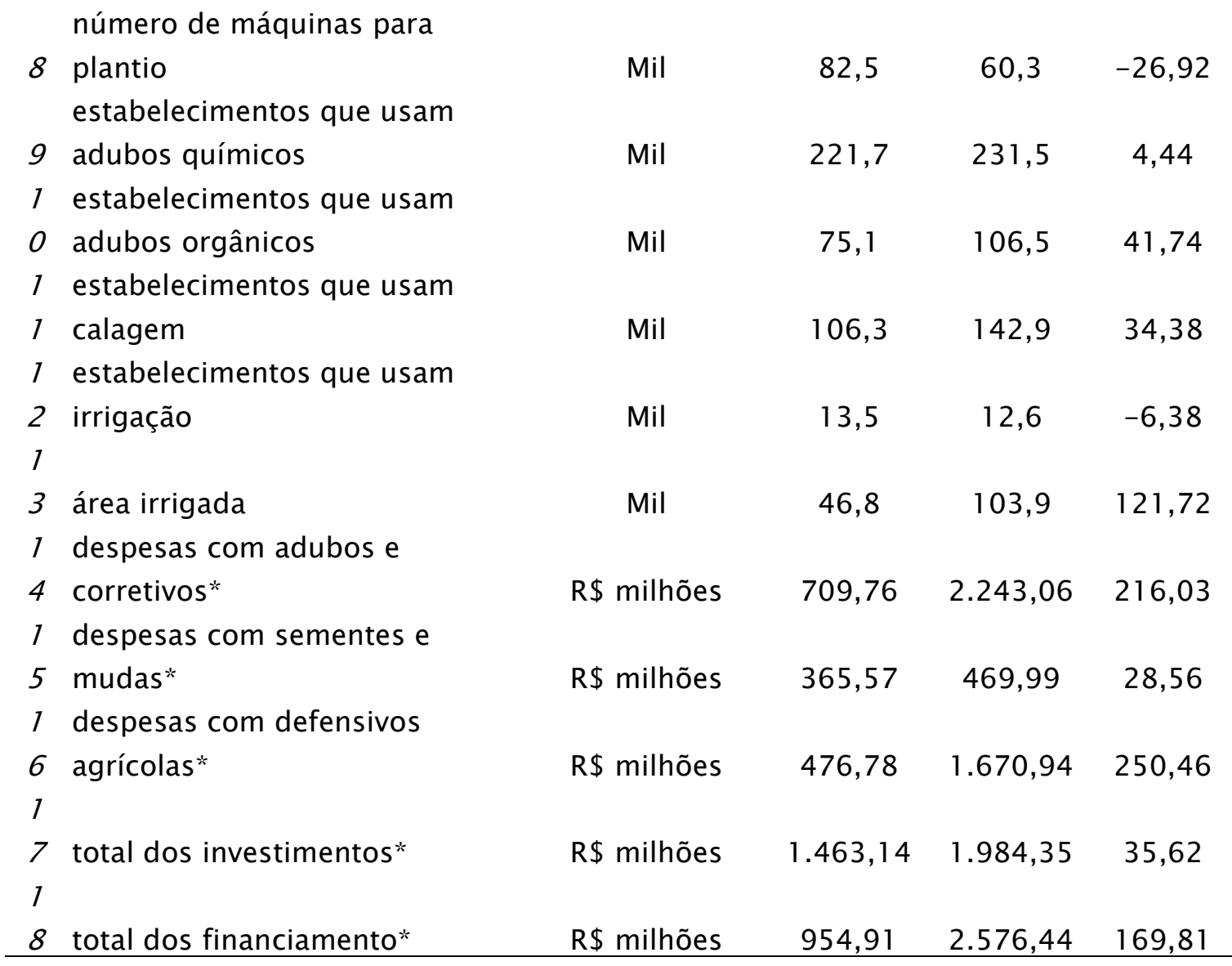

Fonte: Resultados da pesquisa (com base nos censos agropecuários de 1995 e 2006). $\left(^{*}\right)$ As variáveis monetárias possuem valores em Reais $(R \$)$ e estes foram corrigidos para 2006 com base no IPCA.

Com relação às variáveis que englobam diretamente as inovações físico-químicas, merece destaque adubos químicos (estabelecimentos que usam). De um total de 371 mil estabelecimentos, 231 mil fizeram uso de adubos químicos no ano de 2006; já para 1995, pouco mais de $221 \mathrm{mil}$ dos $369 \mathrm{mil}$ totais utilizaram tal processo. Contudo, quando se verifica a taxa de crescimento dessa variável, verifica-se a menor evolução no período, com cerca de $4 \%$ de crescimento. A segunda de maior montante dentre essas foi calagem (estabelecimentos que usam), com cerca de 106 mil em 1995 e 142 mil estabelecimentos em 2006. Para essa variável registra-se um aumento de, aproximadamente, 36 mil estabelecimentos, representando um acréscimo de 34\% de 1995 para 2006.

Quanto à variável adubos orgânicos (estabelecimentos que usam), apresenta-se como a de menor uso para ambos os anos. Em 1995 apenas 75 mil faziam uso de adubos orgânicos, cerca de $20 \%$ dos estabelecimentos. Quando comparado ao uso de adubos químicos, esse 
montante representa aproximadamente um terço. No ano de 2006, por sua vez, o número de estabelecimentos que utilizaram adubo orgânico atinge $105 \mathrm{mil}$ (aproximadamente $30 \%$ do total), representando uma taxa de crescimento entre os dois anos superior a $40 \%$.

Após verificar a menor utilização de inovações mecânicas (porém uma intensificação, por meio de utilização de uma maquinaria mais eficiente, potente e produtiva) e a crescente utilização de inovações não mecânicas, discute-se a variável investimento. Essa cresce $35 \%$ no período, saindo de $R \$ 1,4$ bilhões em 1995 para, aproximadamente, $R \$$ 2 bilhões no ano de 2006, sendo que, grande parte desse montante, ou seja, $R \$ 1,6$ bilhões foram direcionados a investimentos em inovações de cunho não físico-químicas, biológicas ou agronômicas. Por sua vez, destes $R \$ 1,6$ bilhões cerca de $R \$ 6$ milhões foram investidos em mecanização.

Finaliza-se este item discutindo o item financiamento, que apresenta expressivo crescimento no período, quase triplicando seu montante; com crescimento próximo a $170 \%$, esse item supera a casa dos 2,5 bilhões de reais no ano de 2006 no estado. Desses R $\$ 2,5$ bilhões destinados ao setor agrícola, a sua maior parte ( $R \$ 2$ bilhões) é proveniente dos bancos, não sendo possível precisar se estatais ou privados.

Os resultados da análise descritiva permitem concluir que 0 processo de modernização agrícola recente no Paraná se caracteriza pelas inovações físico-químicas e biológicas e na utilização de uma maquinaria mais moderna, mesmo que em menor número. Tal fato evidencia que o ganho de produção e produtividade verificado no setor está pautado nesse conjunto de transformações.

\subsection{Discussão dos resultados da Análise Fatorial}

Para verificar a viabilidade da metodologia de análise fatorial para os dados utilizados nesta pesquisa, foram utilizados os testes KaiserMeyer-Olkin (KMO) e o Teste Bartlett de esfericidade. O primeiro, de acordo com Corrar et al. (2012), mede o grau de correlação parcial entre as variáveis, ou seja, indica o grau de explicação dos dados a partir dos fatores encontrados na análise fatorial. Já o Teste Bartlett de esfericidade, segundo Hair et al. (2005), é um teste estatístico para presença de correlação entre as variáveis. O teste indica se a matriz de 
correlação é uma matriz identidade, ou seja, correlação zero entre as variáveis, resultado que torna inviável o uso da análise fatorial.

Segundo Hair et al. (2005), um KMO superior a 0,50 torna possível a utilização da análise fatorial. Neste estudo, os valores encontrados para $1995(0,748)$ e $2006(0,649)$ revelam a boa aderência e adequação da análise fatorial aos indicadores de modernização utilizados. No caso do teste de Bartlett de esfericidade, segundo Corrar et al. (2012), para que seja possível a aplicação da análise fatorial, é necessário que o seu teste de significância não ultrapasse 0,05 , o que foi observado para a amostra em questão. A análise dos valores obtidos do KMO e teste Bartlett de esfericidade para ambos os anos permite concluir que a amostra utilizada é adequada ao procedimento de análise fatorial, ou seja, é viável e adequado o emprego de análise fatorial para formação de fatores, ou melhor, novas variáveis criadas a partir dos 35 indicadores.

A utilização do método de Análise dos Componentes PrincipaisACP selecionou, para 1995, 19 variáveis e gerou, a partir destes componentes, seis fatores principais com raízes características superiores a um. Em 2006, foram selecionadas 24 variáveis e obtidos sete fatores. Tais resultados foram obtidos considerando os critérios da matriz de anti image correlation, da tabela de communalities e das cargas fatoriais. Ressalta-se, ainda, que tais resultados já consideram a rotação ortogonal do tipo varimax para facilitar a interpretação dos fatores. Segundo Corrar et al. (2012), esse é o tipo de rotação mais usado, caracterizando-se por minimizar a ocorrência de uma variável que possuir altas cargas fatoriais para fatores distintos, facilitando, assim, a identificação com um único fator.

A partir das informações da Tabela 2, pode-se concluir que, para 1995, os seis fatores gerados explicam $88,15 \%$ da variância total das variáveis selecionadas. Para 2006, foram identificados sete fatores, que explicam $89,43 \%$ do comportamento das variáveis.

Tabela 2. Fatores obtidos pelo método ACP para o Paraná 1995 e 2006

\begin{tabular}{|c|c|c|c|c|c|}
\hline Ano & Fator & $\begin{array}{c}N^{o} \\
\text { variáveis }\end{array}$ & Raiz & $\begin{array}{c}\text { Variância explicada } \\
\text { pelo fator (\%) }\end{array}$ & $\begin{array}{c}\text { Variância } \\
\text { acumulada (\%) }\end{array}$ \\
\hline \multirow{4}{*}{$\begin{array}{l}\text { ผn } \\
\text { Оे }\end{array}$} & & & 5,69 & & \\
\hline & 1 & 7 & 1 & 29,950 & 29,950 \\
\hline & & & 2,75 & & \\
\hline & 2 & 3 & 3 & 14,491 & 44,441 \\
\hline
\end{tabular}




\begin{tabular}{|c|c|c|c|c|c|}
\hline & & & 2,51 & & \\
\hline & 3 & 3 & 8 & 13,251 & 57,692 \\
\hline & & & 1,99 & & \\
\hline & 4 & 2 & 2 & 10,484 & 68,176 \\
\hline & & & 1,95 & & \\
\hline & 5 & 2 & 0 & 10,263 & 78,440 \\
\hline & & & 1,84 & & \\
\hline & 6 & 2 & 5 & 9,713 & 88,153 \\
\hline & & & 3,90 & & \\
\hline & 1 & 4 & 8 & 18,609 & 18,609 \\
\hline & & & 3,04 & & \\
\hline & 2 & 4 & 6 & 14,505 & 33,114 \\
\hline & & & 2,87 & & \\
\hline & 3 & 3 & 7 & 13,701 & 46,816 \\
\hline ஜ & & & 2,58 & & \\
\hline$\stackrel{ }{\sim}$ & 4 & 3 & 9 & 12,370 & 59,186 \\
\hline & & & 2,43 & & \\
\hline & 5 & 3 & 4 & 11,588 & 70,774 \\
\hline & & & 1,96 & & \\
\hline & 6 & 2 & 5 & 9,358 & 8,132 \\
\hline & & & 1,95 & & \\
\hline & 7 & 2 & 4 & 9,306 & 89,438 \\
\hline
\end{tabular}

Fonte: Resultados da pesquisa.

Diante de resultados que validam o uso da análise fatorial, faz-se, a seguir, a classificação das variáveis de acordo com as cargas fatoriais. A partir da rotated component matrix, busca-se identificar as variáveis componentes de cada fator para cada ano estudado. A partir de sua carga fatorial, define-se em qual fator se encaixa cada variável.

Obtidas as cargas fatoriais e a classificação dos fatores com seus respectivos indicadores constituintes (Tabela 5 do APÊNDICE I), utilizouse os escores fatoriais de cada fator criado para cada município no estado. A partir dessas novas variáveis (fatores), foi possível criar e calcular o IMA para ambos os anos (os valores de todos os fatores para ambos os anos, bem como o IMA de todos os municípios). Antes, ressalta-se que fez-se uso para ambos os anos da interpolação.

Após interpolação do IMA, calculou-se a média e o desvio padrão e, a partir destes, criaram-se as seguintes classes de municípios quanto ao IMA. Para valores maiores que 0 e menores ou iguais a 1 e desvio padrão abaixo da média, o índice é Muito Baixo; municípios com IMA maior que 1 e valor do desvio padrão menor ou igual a $1 / 2$, é classificado 
como Baixo; municípios em torno da média com limites para cima e para baixo de $1 / 2$ desvio padrão foram considerados Médio; Valores do IMA maiores que $1 / 2$ desvio padrão acima da média e menores ou igual a 1 desvio padrão acima da média foram considerados como Alto; e, por fim, tem o IMA de Muito Alto, com valores superiores a um desvio padrão acima da média. A Tabela 3 apresenta os valores para os critérios de classificação do IMA.

Tabela 3. Critérios de classificação do IMA - Paraná 1995 e 2006

\begin{tabular}{|c|c|c|c|}
\hline & Medidas & 1995 & 2006 \\
\hline \multicolumn{2}{|c|}{ Média } & 0,260 & 0,259 \\
\hline \multicolumn{2}{|c|}{ Desvio Padrão } & 0,171 & 0,161 \\
\hline \multirow{5}{*}{ 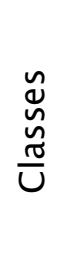 } & Muito Baixo & $0<\mathrm{IMA} \leq 0,089$ & $0<\mathrm{IMA} \leq 0,098$ \\
\hline & Baixo & $0,089<\mathrm{IMA} \leq 0,174$ & $0,098<\mathrm{IMA} \leq 0,178$ \\
\hline & Médio & $0,174<\mathrm{IMA} \leq 0,345$ & $0,178<\mathrm{IMA} \leq 0,339$ \\
\hline & Alto & $0,345<\mathrm{IMA} \leq 0,431$ & $0,339<\mathrm{IMA} \leq 0,419$ \\
\hline & Muito Alto & $0,431<\mathrm{IMA} \leq 1$ & $0,419<$ IMA $\leq 1$ \\
\hline
\end{tabular}

Fonte: Resultados da pesquisa.

As médias e desvios padrões do IMA (Tabela 3) correspondentes aos dois anos da análise se apresentaram próximos, praticamente não se verificam alterações, consequentemente, os intervalos das classes criadas ficam próximos, apresentando certa semelhança entre os critérios estabelecidos para cada ano de acordo com a média e desvio padrão correspondente.

Para ambos os anos, verificou-se o maior número de municípios concentrados na classe de média modernização, respectivamente, 168 e 140 municípios para os anos de 1995 e 2006. Nas classes de alta modernização (Alto e Muito Alto), tem-se praticamente o mesmo montante de municípios (103 municípios para 1995 e 111 para o ano de 2006 , representando, respectivamente, $25,8 \%$ e $27,8 \%$ do total de municípios), sendo oito municípios a mais para o ano de 2006 - todos na classe Alto. Com relação às duas classes de baixa modernização (Muito Baixo e Baixo), o ano de 2006 apresenta um número maior de municípios, 148 contra 128 do ano de 1995, representando, respectivamente, $37,0 \%$ e $32,0 \%$ do total de municípios. Assim, verificase certo equilíbrio entre as classes baixo, médio e alto nível de modernização (Tabela 4). 
Tabela 4 - Distribuição dos Municípios do Paraná segundo o IMA

\begin{tabular}{cccccccc}
\multicolumn{8}{c}{$1995 / 2006$} \\
\multirow{2}{*}{ Ano } & \multicolumn{8}{c}{ Classes do IMA } & \multirow{2}{*}{ Total } \\
\cline { 2 - 6 } & Muito baixo & Baixo & Médio & Alto & Muito Alto & \\
\hline 1995 & 51 & 77 & 168 & 45 & 58 & 399 \\
2006 & 55 & 93 & 140 & 53 & 58 & 399 \\
\hline
\end{tabular}

Fonte: Resultados da pesquisa.

$\mathrm{Na}$ classe Muito Alto, para os anos de 1995 e 2006, foram identificados 58 municípios com elevados IMA e que apresentaram os melhores desempenhos do Paraná. Para a classe Muito Baixo nível de modernização, para 1995, existiam 51 e, para 2006, eram 55. Após a criação dos fatores e geração dos scores como novas variáveis, calculou-se, conforme explicado na metodologia, o IMA e realizou-se a análise espacial.

\subsection{Análise Espacial do IMA}

O valor calculado do / de Moran Global para o IMA de 1995 $(0,3912)$, mostrou-se acima do valor esperado $(-0,0025)$, o que caracteriza presença de autocorrelação positiva entre os municípios paranaenses. O IMA calculado para 2006 apresentou um / de Moral Global de 0,3747, verificando-se, também, autocorrelação positiva entre os municípios para este ano. Para ambos os casos, o / de Moran Global se mostrou significativo a $1 \%$.

De acordo com Anselin (1995), Perobelli et al. (2007) e Almeida (2012), a estatística / de Moran é uma medida de cunho global, não sendo desta forma capaz de constatar esta correlação localmente, fazendo-se necessária, portanto, a utilização do diagrama de dispersão de Moran.

A partir do diagrama de dispersão de Moran (Figura 3), percebese que o coeficiente de inclinação da reta é positivo para os dois anos da análise, ou seja, existe uma concentração de municípios nos quadrantes Alto-alto e Baixo-baixo. A análise dos dados para 1995 permite verificar que 131 municípios encontram-se no quadrante A/toalto, representando $32,83 \%$ do total, e no quadrante Baixo-Baixo foram identificado 175 municípios, correspondendo a 43,85\% dos municípios paranaenses. Verifica-se que 306 (76,69\% dos 399 municípios) estão 
nos quadrantes Alto-alto ou Baixo-baixo - nos quadrantes Alto-baixo e Baixo-alto registraram-se, respectivamente, $33(8,27 \%$ do total) e 60 (15,04\% do total) municípios.

Para 2006, 137 municípios (34,33\%) estão no quadrante A/to-alto, enquanto que os outros 166 (representando $41,60 \%$ ), no quadrante Baixo-baixo. Quanto aos quadrantes Alto-baixo e Baixo-alto, que caracterizam autocorrelação negativa, foram identificados no primeiro 42 municípios e 54 no segundo, o que representa no total de municípios respectivamente $10,53 \%$ e $13,53 \%$ do total.

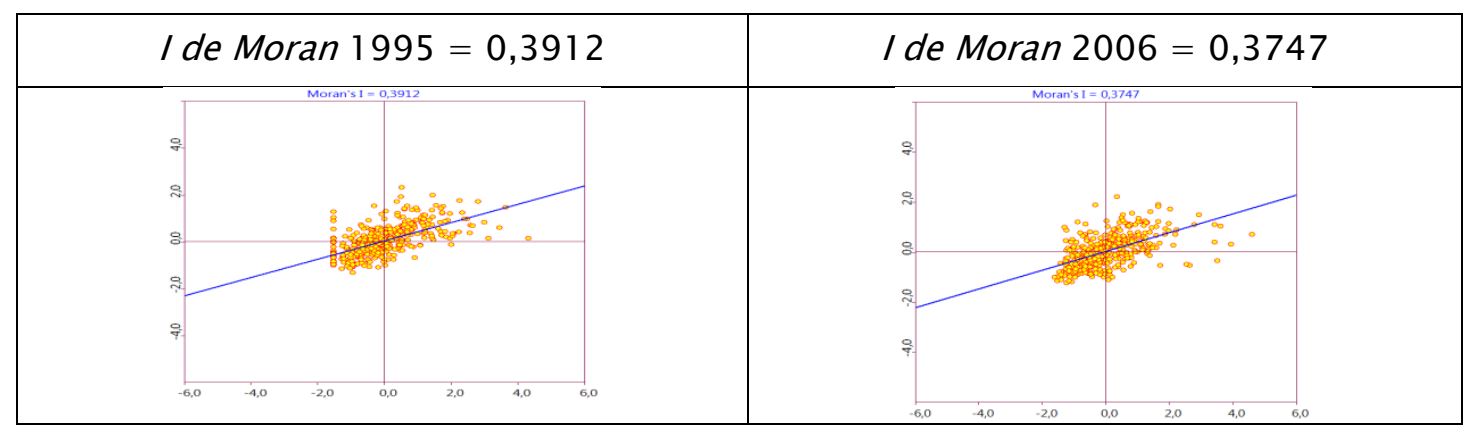

Figura 3. Diagrama de Dispersão de Moran do IMA para o Paraná - 1995 e 2006 Fonte: Resultados da pesquisa - gerado pelo software GEODA

A análise dos resultados do / de Moran Global e do diagrama de dispersão de Moran permitem inferir que, no Paraná, existem agrupamentos ou clusters de municípios pela similaridade de IMA. Os municípios com IMAs mais elevados tendem a ser rodeados por municípios com IMAs elevados, bem como municípios com IMAs menores apresentam em seu entorno municípios com IMAs baixos.

Uma análise complementar é o mapeamento das variáveis. Os mapas de significância do / de Moran Local para o IMA dos municípios paranaenses mostraram que, para o ano de 1995, 118 municípios foram significativos ao nível de $5 \%$ de significância estatística (ou inferior). Para 2006, registraram-se 126 municípios significativos ao nível de 5\% de confiança (ou inferior). Tais resultados, respectivamente, representam 29,55\% e 31,57\% dos 399 municípios do Paraná.

O mapa de clusters (Figura 4) permite identificar, para ambos os anos, a formação de clusters de alto e baixo IMA. Para o ano de 1995, detecta-se a formação de quatro clusters definidos como de BaixoBaixo IMA, sendo um de grande magnitude, um de média e outros dois de pequeno porte. Para esse mesmo ano, os clusters Alto-Alto são seis 
no estado.

Para 2006, podem-se identificar três significativos clusters de baixo IMA, sendo um na parte central do estado, um na mesorregião Noroeste Paranaense e um na parte leste do estado. Quanto aos classificados como Alto-Alto, identifica-se novamente a formação de seis clusters, sendo nas mesmas áreas daqueles identificados em 1995. Dentre esses, quatro apresentam um número maior de municípios, enquanto dois agregam até cinco municípios.

Dada a semelhança na formação dos clusters nos dois anos, tanto de baixo como de alto IMA, analisam-se os principais clusters (alto e baixo) de forma conjunta. Iniciando pelos clusters de baixo nível de modernização, pode-se observar, na região central do estado o maior cluster do ano de 1995 e o segundo maior de 2006. Em 1995 este englobava 36 municípios (Cluster 1 - Figura 4), estendendo-se por 6 mesorregiões estaduais: inicia-se no Norte Pioneiro, expande-se pelo Norte Central e Centro Oriental e atinge as mesorregiões Centro Sul, Sudeste e Oeste Paranaense. Dessa forma, esse cluster concentra maior parte dos municípios nas mesorregiões Norte Central, Centro Sul e Oeste Paranaenses, ou seja, tem seu núcleo principal nestas três mesorregiões. Para o ano de 2006 (Cluster 2 - Figura 4), o cluster Baixo-Baixo mostra-se em menor proporção e abrange 5 mesorregiões (Centro Oriental, Norte Central, Centro Ocidental, Centro Sul e Oeste Paranaense), no entanto, apresenta núcleo em três (Norte Central, Centro Sul e Oeste) e é composto por 26 municípios. 


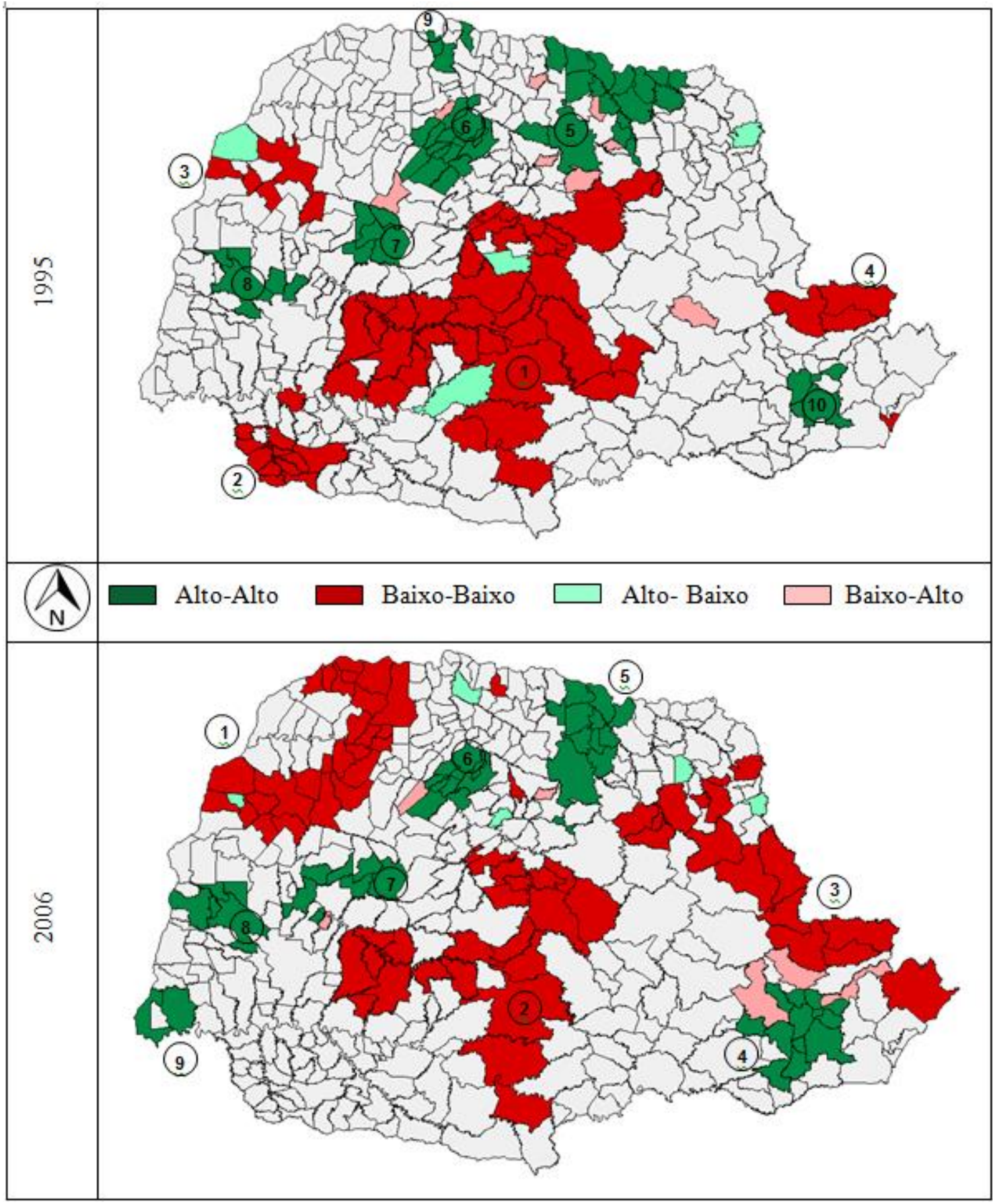

Figura 4 - Mapa de Clusters do IMA - Paraná 1995 e 2006.

Fonte: Resultados da pesquisa - Gerado no GEODA.

De acordo com o Instituto Paranaense de Desenvolvimento Econômico e Social- IPARDES (2004), na área correspondente aos clusters Baixo-Baixo, a atividade econômica predominante é a agropecuária. Cerca de $40 \%$ do pessoal ocupado, encontra-se no setor agropecuário, caracterizando-se, assim, como uma área rural. As famílias são predominantemente pobres, inclusive com grande número de municípios em estado crítico de pobreza, pois mais de $40 \%$ das 
famílias é de classe pobre. Corroborando tais informações, registra-se um baixo IDH, tendo a grande maioria dos municípios IDH abaixo da média estadual. Assim, apesar de o setor agropecuário ocupar o maior contingente de pessoas, este não se mostra grande produtor de renda para as famílias da região.

Outro aspecto a se destacar é quanto ao relevo e potencial do solo. Segundo o IPARDES (2004), a maior parte dessa região se encontra em área de solo inapto, com restrição ou de qualidade regular, dificultando, desta forma, um melhor processo de modernização e, consequentemente, ganhos de produção e produtividade.

Com relação à parte localizada na mesorregião Centro Sul (núcleo do (luster), verificam-se alguns aspectos restritivos a um mais intenso processo de modernização. Apesar de $50 \%$ do território da mesorregião ser pouco ondulado e, consequentemente, apto à utilização de implementos e uso de conservação dos solos, parte da mesorregião (30\%) apresenta relevo ondulado, não apto à agricultura mecanizada, bem como vulnerabilidade erosiva. Outra área da mesorregião mostrase fortemente ondulada (atinge até mais $24^{\circ}$ ), inapropriada ao uso de implementos mecanizáveis e com restrições à pecuária e reflorestamento. Existem, inclusive, áreas inaptas à agricultura, devido revelo montanhoso encontrado em alguns municípios. (IPARDES, 2004)

Com relação à formação de clusters de alto índice de modernização agrícola, tem-se novamente alguns localizados em áreas semelhantes para ambos os anos. O cluster mais ao norte do Estado aparece nos dois anos e agrega municípios das mesorregiões Norte Central e Norte Pioneiro, sendo em 1995 (Cluster 5 - Figura 4) formado por 17 municípios e no ano de 2006 (Cluster 5 - Figura 4) composto por 11 municípios das mesmas mesorregiões.

A área coberta pelo cluster Alto-alto apresenta municípios com IDH altos, como o caso de Londrina e Ibiporã. No que se refere às atividades econômicas, segundo o IPARDES (2004), os municípios correspondentes possuem um setor agropecuário forte. Quanto ao relevo e uso potencial do solo, o cluster encontra-se (as duas mesorregiões) em terreno cujo relevo é plano e apresentam ondulações suaves (até $12^{\circ}$ de declividade), o que o classifica como apto à agricultura, inclusive mecanizada (o uso de força mecânica da produção agropecuária é um dos mais altos do Estado), bem como à pecuária e ao reflorestamento. 
$\mathrm{Na}$ mesorregião Norte Pioneiro, verifica-se a predominância das culturas de soja e trigo, enquanto que a parte do Norte Pioneiro, com exceção do Município de Londrina (que apresenta uma pauta mais diversificada), onde predomina o cultivo de soja. Segundo o IPARDES (2004), na região, tem-se alta produtividade, sendo esta confirmada no estudo de Pavan (2013), que também identificou índices de produtividade de médios para altos. Quanto ao VBP, de acordo com Pinheiro (2007), registram-se, nesta área, valores acima da média, ou seja, de médio e altos VBP's. Llanillo et al. (2006) classificam a área como de agricultura moderna de grãos, bastante especializada, com pouca terceirização e aluguel de máquinas, grande utilização de mão de obra permanente e de pouca pecuária.

Posteriormente, destaca-se o cluster localizado a sudeste do anteriormente citado. Em 1995 (Cluster 6 - Figura 4) agregava 15 municípios das mesorregiões Norte Central e Centro Ocidental, enquanto que para 2006 (Cluster 6 - Figura 4) é formado por nove municípios do Norte Central. O cluster de IMA elevado apresenta terrenos com boa pluviosidade e qualidade da terra; municípios com IDH acima do IDH estadual, e setores agropecuário, industrial (inclusive agroindústria) e serviço bem desenvolvidos. Quanto ao relevo e uso potencial do solo, segundo o IPARDES (2004), as condições são semelhantes ao anterior: relevo de plano e ondulações suaves, (até $12^{\circ}$ de declividade), classificado como bom, sendo apto à agricultura mecanizada bem como à pecuária e ao reflorestamento. Com relação ao uso potencial, os solos são de boa qualidade e fertilidade e aptos à produção agrícola. No que tange às atividades agropecuárias, predomina na área do cluster o cultivo de soja, representando mais de $40 \%$ da pauta de culturas. Quanto ao VBP, segundo Pinheiro (2007), a área apresenta altos valores, inclusive maiores que os do cluster anteriormente analisado.

Em seguida, destaca-se o cluster com municípios da mesorregião Centro Ocidental e Oeste Paranaense. Em 1995, este agregava cinco municípios, enquanto, em 2006, conforme o Cluster 7 apresentado na Figura 4, passa a ser formado por seis municípios. O cluster concentrado basicamente na porção mais centro-oeste da mesorregião Centro Ocidental, e encontra-se em uma área de municípios com IDH abaixo da média estadual e nacional, predominante com pessoas ocupadas nos setores agropecuário e de serviços, com baixo número de 
famílias classificadas como pobres (à exceção de dois municípios). Quanto ao relevo e uso potencial do solo, segundo o IPARDES (2004), a mesorregião como um todo apresenta $77 \%$ de sua área apta à agropecuária mecanizada. O solo é bom ou regular, com problemas somente de baixa fertilidade natural do solo. Contudo, tal problema é compensado pela modernização com uso de melhoramento genético das sementes e insumos químicos para elevação da fertilidade dos solos e controle das pragas e doenças.

Quanto à mecanização, esse cluster apresenta um dos maiores índices de uso de maquinaria do Estado, inclusive representando redução do nível de pessoal ocupado no setor primário. Com relação às atividades agropecuárias, de acordo com IPARDES (2004), destaca-se o cultivo de grãos, sobretudo nas culturas de soja e milho, que respondem a mais de $60 \%$ do que é produzido. Salienta-se, ainda, a alta produtividade agropecuária na área de ocorrência do cluster. O presente trabalho corrobora os resultados do estudo de Pavan (2013), pois também se verifica na região elevado nível de produtividade.

Outro cluster identificado é o localizado no Oeste Paranaense, agregando tanto em 1995 como em 2006 (Clusters cinco em 1995 e 2006 - Figura 4) o mesmo número de municípios (5), e apesar das variações nas composições, tem-se o município de Toledo como núcleo nos dois períodos. A Mesorregião Oeste, área de localização do cluster, apresenta alto IDH municipal (acima de 0,80 ), superiores ao estadual e nacional. Com relação aos setores econômicos, tem-se um setor primário e um setor de serviços bem desenvolvidos, sendo este último, o maior empregador. Quanto ao setor industrial, destaca-se o forte desempenho da agroindústria, sobretudo a jusante, em que se destaca o cooperativismo.

Com relação ao fator relevo e o uso potencial do solo dessa mesorregião, especificamente na área de localização do cluster, conforme IPARDES (2004), nesta área, o relevo é suavemente ondulado, com declividade até $6^{\circ}$, e as terras são aptas ao desenvolvimento da agropecuária mecanizada e manejo florestal. Porém, são observadas áreas inundáveis, com restrição ao uso de mecanização. Quanto ao uso potencial, observam-se solos férteis de tipos bom e regular, potencialmente aptos para a produção agropecuária, com práticas agrícolas de alto nível tecnológico, intensiva em insumos, melhoramento e conservação das condições das terras e lavouras. Há mecanização nas 
várias etapas do processo produtivo agrícola, com baixo emprego de mão de obra no setor.

Quanto à utilização das terras, predominam as culturas de soja, milho, trigo e, secundariamente, pastagens. Articulada com a agroindústria nessas regiões, verifica-se a inserção no mercado internacional e o processo de modernização, apoiado na mecanização, quimificação e genética, fatores que contribuem com o significativo aumento da produtividade e consequente aumento da produção, sobretudo do milho e soja. Outro aspecto importante na área é a criação de aves e suínos, que em 2001 representava 30\% dos rebanhos do Paraná. Este desempenho também foi confirmado pelos trabalhos de Pavan (2013) e Pinheiro (2007).

Por fim, identifica-se nos dois anos o cluster localizado na mesorregião Metropolitana de Curitiba, mais precisamente no entorno da capital. Segundo a Figura 4, o cluster 4, em 1995, era formado por cinco municípios, enquanto que, em 2006, (Cluster 4 ) mostra-se como maior cluster em número de municípios de alto nível de modernização agrícola do Paraná, agregando 13 municípios. O cluster formado pela capital Curitiba e os municípios de seu entorno apresenta desde IDH acima de 0,80 (Curitiba e mais três municípios) até índices abaixo do IDH estadual e nacional. Segundo o IPARDES (2004), mesmo nesses municípios de IDH mais favoráveis, verifica-se um grande contingente populacional em situação de carência. Predominam os setores secundário e terciário, contudo, o setor primário é mais diversificado quando comparado às demais mesorregiões.

No tocante ao fator relevo e o uso potencial do solo, conforme IPARDES (2004), nas áreas em que se localizam estes dois clusters, o relevo mostra-se com menor porcentagem de solos aptos à agropecuária (26\%), e na porção central e sul apto à produção agrícola, porém, sujeitos a erosão e a baixa fertilidade do solo.

Nesse cluster, a atividade agropecuária é condicionada à demanda e dinâmica da própria mesorregião. Conforme IPARDES (2004), a produção da região é diversificada, porém com ênfase à especialização em culturas intensivas como as olerículas (convencionais e orgânicas) e frutas. As culturas que mais se destacam são: milho, feijão, batata inglesa, tomate, cebola. 


\section{CONCLUSÃO}

O presente trabalho mensurou e analisou o nível de modernização agropecuária e a sua localização espacial no Estado do Paraná para anos de 1995 e 2006. Como ferramentas, foram utilizadas a análise fatorial e análise exploratória de dados espaciais. Inicialmente, as variáveis foram selecionadas e, após a aplicação de filtros, utilizaram-se 19 e 21 , respectivamente, para 1995 e 2006, a partir das quais foram gerados os fatores para a construção do IMA.

Para o ano de 1995, o método de ACP gerou seis fatores principais que explicam $88,15 \%$ da variância dos dados originais. Em 2006, foram identificados sete fatores que explicaram $89,43 \%$ da variância dos dados originais. Com relação à composição dos fatores, percebe-se alguma semelhança entre os dados do Censo para 1995 e 2006. De maneira geral, os indicadores que mais contribuem na formação do IMA, e que mais peso exerceram, estão agrupados nos primeiros fatores e correspondem à maquinaria, adubos, defensivos e irrigação.

Para o censo de 1995, o fator que explica maior variância dos dados e exerce maior influência sobre o IMA é formado pelos indicadores referentes à maquinaria e despesas com adubos e corretivos, sementes e defensivos agrícolas. O segundo e terceiro fatores são formado pelos indicadores de irrigação e de calagem, respectivamente. Para o censo de 2006, o primeiro fator é formado por indicadores de maquinaria (tratores, máquinas para plantio e colheita), o segundo é constituído pelos indicadores de adubos, corretivos e defensivos agrícolas e o terceiro e quarto fatores representam indicadores de irrigação.

Portanto, os indicadores referentes à maquinaria, adubos e corretivos, sementes e mudas, defensivos agrícolas e irrigação têm alta contribuição para a modernização agrícola do Paraná. Por outro lado, indicadores de investimento, calagem, e financiamento formaram fatores com menor poder de explicação e, assim, desempenham baixa contribuição para o processo de modernização agrícola do Estado.

Com relação aos resultados do IMA, tem-se praticamente a mesma composição em ambos os anos analisados. A média do Estado é praticamente a mesma nos dois anos, situando-se em torno de 0,259 e pequenos desvios padrões. 
Com relação aos clusters de baixo IMA, estes ocorrem geralmente em áreas de baixo IDH, de relevo e solo inaptos ou com restrições à mecanização, com menor fertilidade de solo, vulneráveis à erosão, baixa produtividade agropecuária e baixa capitalização. Já os clusters de alto IMA ocorrem em áreas com maior IDH, com relevo apto à mecanização, solos mais férteis e com menor restrição à produção agrícola, relacionados, principalmente, à alta produtividade e alta capitalização. Esses clusters baseiam-se, em sua maioria - com exceção do cluster da mesorregião Metropolitana de Curitiba, que tem por base olerículcultura e hortifruticultura -, na agricultura moderna de grãos, fortemente mecanizada, sobretudo especializada no cultivo de soja e milho.

Dessa forma, pode-se concluir que, além de mensurar o IMA, foi possível identificar padrões semelhantes de modernização agrícola no Paraná, sendo estes fortemente relacionados ao tipo de relevo, fertilidade do solo e produtividade agrícola, sobretudo, ao tipo de cultura desenvolvida em cada região e a proximidade de centros urbanos maiores. A forte relação da modernização com o tipo de relevo apresenta-se como um fator preponderante para o processo de modernização, visto que o indicador de maior contribuição para o IMA dos municípios do Paraná refere-se à maquinaria, que se encontra fortemente relacionado ao tipo de relevo.

Ademais, deve-se levar em consideração, também, que o IMA para o Paraná esteve relacionado ao tipo de cultura de cada região, em que existem evidências de que regiões onde o agronegócio em larga escala ou exportador está presente, os valores de IMA foram maiores, além do que, estas regiões concentram clusters de alto desenvolvimento, sinalizando sinergia. Como tal análise está fora do escopo deste estudo, não se analisou a relação de causa e efeito nesse processo, mas, para futuras pesquisas, sugere-se a análise do IMA em relação à cultura de cada região e que se busque investigar a relação entre modernização e tipo de cultura, assim como os determinantes de localização destas culturas.

\section{REFERÊNCIAS}

ALMEIDA, E. Econometria Espacial Aplicada. Alínea: Campinas, 2012. 
ALMEIDA, E. S. de; PEROBELLI, F. S.; FERREIRA, P. G. C. Existe convergência espacial da produtividade agrícola no Brasil? RER, Rio de Janeiro, vol. 46, n. 01, p. 031-052, jan/mar 2008.

ANSELIN. Local Indicators of Spatial Association - LISA. Geographical Analysis, 27, n. 2, p. 93-115, 1995.

ANSELIN. Spatial Econometrics. University of Texas at Dallas, School of Social Sciences. Richardson. 1999.

BIVAND, R. S.; PEBESMA, E. J.; RUBIO, V. G. Applied Spatial Data Analysis with R. New York: Springer,2008.

BUAINAIN, A. M ; VIEIRA, A. C. P. ; LIMA, D. A. L. L. A inovação tecnológica na agricultura brasileira - 15 a 19/11/2010. In: VIII Congresso Latinoamericano de Sociologia Rural, 2010, Porto de Galinhas, PE. ALASRU 2010, 2010.

CORRAR, L. J.; PAULO, E.; DIAS FILHO, J. M. (Coodernadores). Análise Multivariada: para cursos de administração, ciências contábeis e economia. São Paulo: Atlas, 2012.

DELGADO, G. C. Expansão e modernização do setor agropecuário no pós-guerra: um estudo da reflexão agrária. São Paulo. Estudos Avançados, v. 15, n. 43, 2001.

Capital financeiro e agricultura no Brasil. Campinas: Ícone/Ed.Unicamp, 1985.

FERREIRA JÚNIOR, S.; BAPTISTA, A.J.M.S.; LIMA, J.E. A modernização agropecuária nas microrregiões do Estado de Minas Gerais. Brasília: SOBER. Revista de Economia e Sociologia Rural, v.42, n.1, 2004.

GRAZIANO DA SILVA, J. A nova dinâmica da agricultura brasileira. Campinas: UNICAMP, 1996. 
. O progresso técnico na agricultura. Cadernos de Difusão de Tecnologia, Brasília/DF, v. 7, n.1, p. 13-46, 1990.

HADDAD, E. A.; PIMENTEL, E. A. Análise da distribuição espacial da renda no estado de Minas Gerais: uma abordagem setorial. São Paulo, $2004 . \quad$ Disponível em: http://www.bnb.gov.br/content/aplicacao/ETENE/Anais/docs/2004analide-da-istribuicao.pdf. Acesso em: 17 nov. 2012.

HAIR, J. et al. Análise Multivariada de Dados. 5. ed. Porto Alegre: Bookman, 2005.

HOFFMANN, R. A dinâmica da modernização da agricultura em 157 microrregiões homogêneas do Brasil. Revista de Economia e Sociologia Rural. Brasília, v. 30, n.4, p.271-290, out/dez. 1992.

IBGE - INSTITUTO BRASILEIRO DE GEOGRAFIA E ESTATÍ́STICA - Sidra Censo Agropecuário. Disponível em <http://www.ibge.gov.br $>$. Acesso em: 2013.

IPARDES - INSTITUTO PARANAENSE DE DESENVOLVIMENTO ECONÔMICO $\mathrm{E}$

SOCIAL. Disponível em: <http://www.ipardes.gov.br>. Acesso em: 2013

IPARDES - INSTITUTO PARANAENSE DE DESENVOLVIMENTO ECONÔMICO $\mathrm{E}$

SOCIAL. Leituras regionais: mesorregiões geográficas paranaenses. Curitiba: 2004.

KAGEYAMA, A.; GRAZIANO DA SILVA, J. F. A dinâmica da agricultura brasileira: do complexo rural aos complexos agroindustriais. Campinas: IE/UNICAMP, Mimeo, 56p, 1987.

KAGEYAMA, A. Desenvolvimento Rural: conceito e medida. Brasília: Cadernos

de Ciência \& Tecnologia, v. 21, n. 3, p. 379-408, set./dez. 2004. 
LLANILLO, F. R.; et.al. Regionalização da agricultura do estado do Paraná, Brasil. Ciência Rural, Santa Maria, RS, v. 36, n.1, 2006.

MARTINE, George. A trajetória da modernização agrícola: a quem beneficia? Lua Nova, São Paulo: CEDEC, n. 23, p. 7-37, mar. 1991.

MIELITZ NeTTO, C.G.A.; MAIA, C.M.; MELO, L. M.. Políticas Públicas e Desenvolvimento Rural no Brasil. 1. ed. Porto Alegre: Editora da UFRGS, 2011 . v. 1.82p.

MELO, C. O.; PARRÉ, J. L. Índice de desenvolvimento rural dos municípios paranaenses: determinantes e hierarquização. Revista de Economia e Sociologia Rural, Rio de Janeiro, v. 45, nº 02, p. 329-365, abr/jun 2007.

PAVAN, Lucca Simeoni. Os determinantes da produtividade agrícola dos municípios paranaenses: uma análise de dados espaciais. 2013. $115 \mathrm{f}$. Dissertação (Mestrado em Economia) -, Universidade Estadual de Maringá, Maringá, 2007.

PEROBELLI, F. S.; et.al. Produtividade do setor agrícola brasileiro (19912003): uma análise espacial. Nova Economia, Belo Horizonte, v. 17, p. 65-91, 2007.

PINHEIRO, Maria Andrade. Distribuição Espacial Da Agropecuária Do Estado Do Paraná: um estudo da função de produção. 2007. 126 f. Dissertação (Mestrado em Economia). Maringá, UEM, 2007.

SALLES FILHO, Sergio Luiz Monteiro. A dinâmica tecnológica na agricultura. 1993. 246 pf. Tese ( Doutorado em Política Científica e Tecnológica). Campinas, UNICAMP, 1993.

SILVA, R.G.; FERNANDES, E. A. Índice relativo de modernização agrícola na região Norte. Viçosa: UFV. Revista de Economia e Agronegócio, vol. 03, n01, p.29-49, abril 2005.

SILVA, R.G.; BAPTISTA, A.J.M.S.; FERNANDES, E. A. Modernização agrícola na região norte: uma aplicação da estatística multivariada. Rio Verde: FESURV. RV Economia, ano 5, $\mathrm{n}^{\circ} 11$, p.20-24, nov. 2003. 
SOUZA, P. M., LIMA, J. E. Intensidade e dinâmica da modernização agrícola no Brasil e nas unidades de federação. Rio de Janeiro: FGV. Revista Brasileira de Economia, v.57, n.4, p.795-824, 2003.

SOUZA, P. M.; et.al. J. Padrão de desenvolvimento tecnológico dos municípios das Regiões Norte e Noroeste do Rio de Janeiro. RESR, Piracicaba, SP, vol. 47, nº 04, p. 945-969, out/dez 2009.

TEIXEIRA, R. F. A. P.; et.al. Análise Espacial da Produtividade de Óleo Vegetal para Produção de Biodiesel na Zona da Mata Mineira. GESTÃO.Org. Revista Eletrônica de Gestão Organizacional, v. 6, p. 278299, 2008.

TYSZLER, Marcelo. Econometria Espacial: Discutindo Medidas para a Matriz de Ponderação Espacial. São Paulo, 2006, 115p. Dissertação (Mestrado). Fundação Getúlio Vargas - Escola de Administração de Empresas de São Paulo.

Submetido em 20/03/2014.

Aprovado em 14/07/2015.

Sobre os autores

Edson Ramos de Medeiros

Mestre em Economia Regional pela Universidade Estadual de Londrina - UEL.

E-mail: edsonrmedeiros@yahoo.com.br

\section{Marcia Regina Gabardo da Camara}

Doutora em Teoria Econômica- FEA/USP. Professora Associada do Departamento de Economia -Universidade Estadual de Londrina.

Endereço: Rua: Rua Belo Horizonte, 734, apto 16, Centro. 86020-060 - Londrina, PR, Brasil.

E-mail:mgabardo@uel.br

\section{Carlos Eduardo Caldarelli}

Doutor em Economia Aplicada ESALQ/USP. Professor Adjunto B - Universidade Estadual de Londrina - UEL.

Endereço: Rua Juiz de Fora, 230 Jardim Champagnat. 86062-680 - Londrina, PR, Brasil. E-mail: caldarelli@uel.br

\section{Vanderlei José Sereia}

Doutor em Administração pela Universidade Nove de Julho - UNINOVE. Professor 
Adjunto B do Departamento de Economia

Endereço: Rua: Silvio Pegoraro, 599 - Apto 1802, Jardim Petrópolis. 86015-490 Londrina, PR, Brasil.

E-mail: sereia@uel.br

\section{APÊNDICE I}

\begin{tabular}{|c|l|}
\hline Variável & \multicolumn{1}{|c|}{ Descrição } \\
\hline$X_{1}$ & área explorada/pessoal ocupado \\
$X_{2}$ & produção/área explorada \\
$X_{3}$ & produção/pessoal ocupado \\
$X_{4}$ & estabelecimentos que usam força mecânica/total de estabelecimentos \\
$X_{5}$ & tratores/área explorada \\
$X_{6}$ & tratores/pessoal ocupado \\
$X_{7}$ & máquinas para colheita/área explorada \\
$X_{8}$ & máquinas para colheita/pessoal ocupado \\
$X_{9}$ & máquinas para plantio/área explorada \\
$X_{10}$ & máquinas para plantio/pessoal ocupado \\
$X_{11}$ & estabelecimentos que usam adubos químicos/área explorada \\
$X_{12}$ & estabelecimentos que usam adubos químicos /pessoal ocupado \\
$X_{13}$ & estabelecimentos que usam adubos químicos/total de \\
$X_{14}$ & estabelecimentos \\
$X_{15}$ & estabelecimentos que usam adubos orgânicos/área explorada \\
$X_{16}$ & estabelecimentos que usam adubos orgânicos/pessoal ocupado \\
$X_{17}$ & estabelecimentos que usam adubos orgânicos/ total de \\
$X_{18}$ & estabelecimentos \\
$X_{19}$ & estabelecimentos que usam calagem/área explorada \\
$X_{20}$ & estabelecimentos que usam calagem/pessoal ocupado \\
$X_{21}$ & estabelecimentos que usam irrigação/área explorada \\
$X_{22}$ & estabelecimentos que usam irrigação/pessoal ocupado \\
$X_{23}$ & estabelecimentos que usam irrigação/ total de estabelecimentos \\
$X_{24}$ & área irrigada/área explorada \\
$X_{25}$ & área irrigada/total de estabelecimentos \\
$X_{26}$ & despesas com adubos e corretivos/área explorada \\
$X_{27}$ & despesas com adubos e corretivos/pessoal ocupado \\
$X_{28}$ & despesas sementes e mudas/área explorada \\
$X_{29}$ & despesas com sementes e mudas/pessoal ocupado \\
\hline
\end{tabular}


Fatores da modernização agrícola no Paraná para os anos de 1995 e 2006

\begin{tabular}{|l|l|}
\hline$X_{30}$ & despesas com defensivos agrícolas/área explorada \\
$X_{31}$ & despesas com defensivos agrícolas/pessoal ocupado \\
$X_{32}$ & total dos investimentos/área explorada \\
$X_{33}$ & total dos investimentos/pessoal ocupado \\
$X_{34}$ & total dos financiamentos /área explorada \\
$X_{35}$ & total dos financiamentos / pessoal ocupado \\
\hline
\end{tabular}

Quadro 1. Descrição e nomenclatura das variáveis utilizadas

Fonte: elaborado pelos autores. 
Edson R. de Medeiros, Marcia R. G. da Camara, Carlos E. Caldarelli, Vanderlei J. Sereia

Tabela 5. Distribuição das variáveis segundo os fatores - Paraná 1995 e 2006

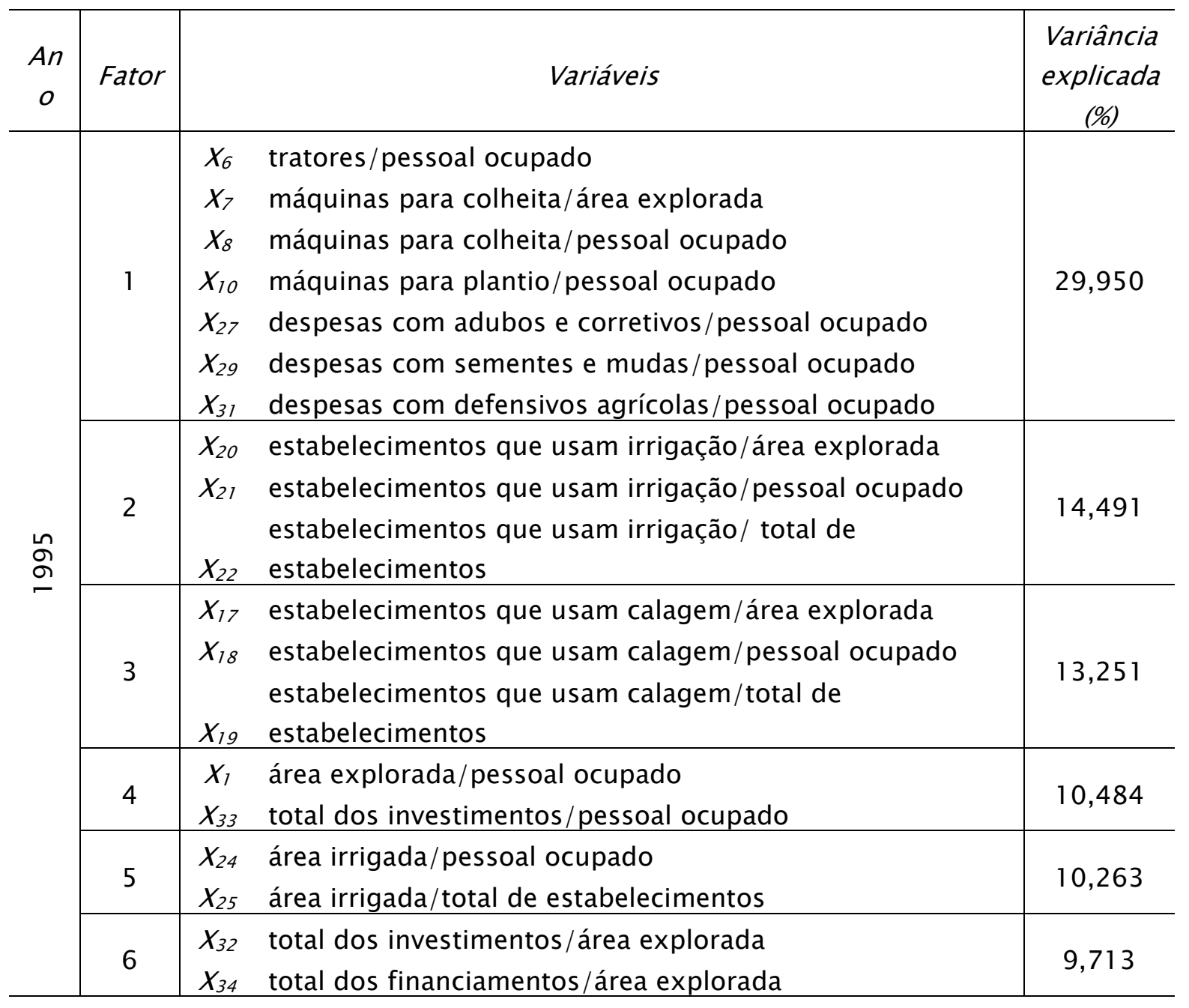

\begin{tabular}{|c|c|c|c|c|}
\hline \multirow{5}{*}{$\begin{array}{l}\stackrel{8}{0} \\
\stackrel{\sim}{0}\end{array}$} & 1 & $\begin{array}{l}X_{4} \\
X_{6} \\
X_{8} \\
X_{10}\end{array}$ & $\begin{array}{l}\text { estabelecimentos que usam força mecânica/total de } \\
\text { estabelecimentos } \\
\text { tratores/pessoal ocupado } \\
\text { máquinas para colheita/pessoal ocupado } \\
\text { máquinas para colheita/pessoal ocupado }\end{array}$ & 18,609 \\
\hline & 2 & $\begin{array}{l}X_{26} \\
X_{27} \\
X_{30} \\
X_{31}\end{array}$ & $\begin{array}{l}\text { despesas com adubos e corretivos/área explorada } \\
\text { despesas com adubos e corretivos/pessoal ocupado } \\
\text { despesas com defensivos agrícolas/área explorada } \\
\text { despesas com defensivos agrícolas/pessoal ocupado }\end{array}$ & 14,505 \\
\hline & 3 & $\begin{array}{l}x_{20} \\
x_{21} \\
x_{22}\end{array}$ & $\begin{array}{l}\text { estabelecimentos que usam irrigação/área explorada } \\
\text { estabelecimentos que usam irrigação/pessoal ocupado } \\
\text { estabelecimentos que usam irrigação/total de } \\
\text { estabelecimentos }\end{array}$ & 13,701 \\
\hline & 4 & $\begin{array}{l}X_{23} \\
X_{24} \\
X_{25}\end{array}$ & $\begin{array}{l}\text { área irrigada/área explorada } \\
\text { área irrigada/pessoal ocupado } \\
\text { área irrigada/total de estabelecimentos }\end{array}$ & 12,370 \\
\hline & 5 & $x_{9}$ & máquinas para plantio/área explorada & 11,588 \\
\hline
\end{tabular}


Fatores da modernização agrícola no Paraná para os anos de 1995 e 2006

\begin{tabular}{|c|c|c|c|}
\hline & $\begin{array}{l}X_{11} \\
X_{17}\end{array}$ & $\begin{array}{l}\text { estabelecimentos que usam adubos químicos/área } \\
\text { explorada } \\
\text { estabelecimentos que usam calagem/área explorada }\end{array}$ & \\
\hline 6 & $\begin{array}{l}X_{15} \\
X_{16}\end{array}$ & $\begin{array}{l}\text { estabelecimentos que usam adubos orgânicos/pessoal } \\
\text { ocupado } \\
\text { estabelecimentos que usam adubos orgânicos/ total de } \\
\text { estabelecimentos }\end{array}$ & 9,358 \\
\hline 7 & $\begin{array}{r}X_{18} \\
X_{19}\end{array}$ & $\begin{array}{l}\text { estabelecimentos que usam calagem/pessoal ocupado } \\
\text { estabelecimentos que usam calagem/total de } \\
\text { estabelecimentos }\end{array}$ & 9,306 \\
\hline
\end{tabular}

Fonte: Resultados da pesquisa. 